\title{
ПРАВОПРЕЕМСТВО И КОНТИНУИТЕТ \\ В МЕЖДУНАРОДНОМ ПРАВЕ
}

Клапас Илиас*

«Мы, Республика Беларусь, Российская Федерация (РСФСР), Украина как государства - учредители Союза ССР... констатируем, что Союз ССР как субъект международного права и геополитическая реальность прехращает свое существование»! .

Этими словами начинается Соглашение о создании Сoдружества Независимых Государств (СНГ), которым, наряду с другими соглашениями, достигнутыми в Алма-Ате в декабре 1991 г., было прекращено существование СССР как субъекта международного права. Однако, может быть, СССР перестал существовать как геополитическая реальность, но его международная правосубъектность все-таки сохранилась?

Постановка такого вопроса может на первый взгляд показаться странной. Но подобный вопрос следует поставить, исходя из теории континуитета, согласно которой Россия считается государством - продолжателем Союза ССР в международно-правовом плане. Можно ли продолжать то, что прекратило существовать? И к тому же можно ли рассматривать Россию как государство, продолжающее Союз ССР, и в то же время как его правопреемника ${ }^{2}$ ? Иными словами, может ли Россия являться одновременно государством-правопреемником и государством-продолжателем Союза ССР? В силу каких обстоятельств и исходя из каких критериев именно Россия (и никакое другое государство из бывших советских республик) продолжает международную правосубъектность Союза ССР?

Чтобы ответить на все эти и многие другие вопросы, которые возникают в результате политических событий, происшедших на территории бывшего СССР, надо сначала составить представление о понятии правопреемства и его соотношении с правосубъектностью.

\section{Понятия правопреемства и континуитета}

В пределах конкретной территории могут произойти события, которые повлекут за собой прекрашение властвования одного государства и начало господства другого.

* Аспирант Афинскооо университета. 
Вследствие этого встает проблема перехода прав и обязанностей от одного государства к другому, которое его замещает.

Роль международного права в таких случаях состоит в выявлении такого рода событий и в определении их юридических последствий. Для обозначения этих интересующих международное право фактических ситуаций и их юридических последствий используется один и тот же термин - «правопреемство». Это объясняет, почему в международно-правовой литературе определение понятия правопреемства всегда представляло собой немалую сложность. Для преодоления этого английским ученым М. Джонсом была предпринята попытка обозначить понятие правопреемства в каждом из названных значений различными терминами: фактические изменения как преемство были названы правопреемством фактическим (succession in fact), наследование государством прав и обязанностей в результате этих изменений - правопреемством правовым (succession in law) ${ }^{3}$.

В Венских конвенциях 1978 и 1983 годов о правопреемстве государств под правопреемством понимается именно фактическое изменение территориальных ситуаций и дается следующее определение: "правопреемство государств" означает смену одного государства другим в несении ответственности за международные отношения какой-либо территории».

С другой стороны, под термином «правопреемство» в международно-правовой литературе подразумевается «переход прав и обязанностей при определенных фактических событиях или ситуациях и в результате этих событий или ситуаций» ${ }^{4}$. Как мы видим, правопреемство в правовом смысле слова включает в себя два компонента. Во-первых, установление правом случаев, при которых происходит правопреемство. Без их обозначения определение не является полным, поскольку переход прав и обязанностей от одного государства к другому может происходить вследствие не только правопреемства, но и, например, международного договора. Вторым компонентом определения является установление того, что права и обязанности переходят от одного государства $\mathbf{R}$ другому. Из этого следует, что «правопреемство предполагает по необходимости наличие двух государств, государства-предшественника и государства-правопреемника, заступающего в определенные права и обязанности своего предшественника»" 5 . Однако необходимость наличия двух государств не означает, что государствопредшественник обязательно перестает сушествовать.

Когда при фактических изменениях, вызывающих правопреемство, государство-предшественник перестает существовать, «когда юридическая личность общества полностью уничтожена", в международно-правовой литературе говорят, что 
имеет место полное правопреемство государств. Если потеряна территория, в то время как личность государства и юридическая ответственность остаются неизменными, то это характеризуется как частичное правопреемство ${ }^{6}$. В основе различия полного и частичного.правопреемства лежит вопрос о непрерывности международно-правовой личности государства, или, как пишут многие авторы, вопрос об идентичности и континуитете.

Boпрос об идентичности и континуитете не относится к объему переходящих при правопреемстве прав и обязанностей от государства-предшественника к государству-правопреемнику, а касается правосубъектности государства-предшественника, а именно ее сохранения. «Проблема идентичности и континуитета государства - это проблема самого его существования... Вопрос о том, когда одно государство является идентичным другому государству, которое предшествовало ему по времени и с которым оно имеет многие общие черты, равен вопросу о том, когда одно государство умерло и другое родилось на его месте или когда старое государство продолжает свою неизменную юридическую личность» ${ }^{7}$.

Континуитет не представляет собой формы правопреемства, а является антиподом прекращению существования государства. Поэтому континуитет не регулируется нормами правопреемства - он является объектом исследования вопроса о субъекте в международном праве. Решение проблемы континуитета предопределяет и решение проблемы правопреемства. Потому что, с одной стороны, вопрос о сохранении юридической личности государства - это вопрос о сохранении носителя прав и обязанностей, а с другой - от этого зависит совокупность прав и обязанностей, которые переходят к государству-преемнику.

Итак, не случайно многие авторы называют вопрос о международной личности государства «ключом к проблеме правопреемства государств». Поэтому, прежде чем пытаться определить временны́е границы сушествования государства и, следовательно, ответить на вопрос о континуитете, необходимо иметь представление о значении темы континуитета для правопреемства.

Значение континуитета для решения проблемы правопреемства

Венские конвенции о правопреемстве государств 1978 и 1983 годов пока не вступили в силу, так как не набрали достаточного числа ратификаций. Однако их принятие, как 
отмечается в преамбуле Конвенции 1978 года о правопреемстве государств в отношении договоров, было продиктовано «необходимостью кодйфикации и прогрессивного развития норм, касающихся правопреемства государств». То есть в конвенциях не только нашли место новые правила, разработанные в ходе конференции, но и были кодифицированы обычные нормы международного права, отражающие всеобшую практику государств, признанную в качестве правовой нормы. Поэтому «можно пользоваться их положениями как отражением норм международного обычая» ${ }^{8}$, что очень важно, поскольку обычные нормы действуют независимо от вступления в силу конвенции, их содержащей.

В Венских конвенциях о правопреемстве 1978 и 1983 годов термины «полное» и «частичное правопреемство», "континуитет» и «идентичность» не используются. Это, конечно, не значит, что международный законодатель упустил из виду важность темы континуитета для правопреемства. В конвенциях употребляются термины «отделение части или частей государства» и "разделение государства».

Вопрос о полном или частичном правопреемстве в случае образования двух или нескопьких государств на территории одного государства связан с вопросом о разделении или отделении государств. Если государство-предшественник перестает существовать и никто из государств не наследует его юридическую личность (случай полного правопреемства), тогда происходит разделение государства. Когда его правосубъектность сохранилась (частичное правопреемство) и произошла замена его двумя или несколькими вновь образовавшимися государствами в несении ответственности за какую-то часть его территории, тогда налицо отделение части или частей государства. При разделении государства каждое из новых государств выступает как преемник. Только при отделении части или частей государства продолжает суцествовать государство-предшественник.

Что касается Конвенции о правопреемстве в отношении договоров, создается впечатление, что в ней не проводятся различия между разделением и отделением государств. И это верно применительно к правопреемству в отношении договоров, находившихся в силе в момент правопреемства. В отношении каждого отдельного государства независимо от того, является ли оно государством-предшественником или государством-преемником, устанавливается обязанность соблюдать все договоры, находившиеся в силе в момент правопреемства и относяшиеся, во-первых, ко всей территории государствапредшественника и, во-вторых, к его собственной территории (ст. 34-35). Предусмотренные исключения из этого правила 
также одинаковы и для государства-преемника, и для государства-предшественника, которое продолжает существовать.

Однако можно сказать, что даже применительно к договорам, находившимся в силе в момент правопреемства, сушествует различие между старым государством и новым. Государство-предшественник не нуждается ни в каком подтверждении того, что оно продолжает быть связанным этими договорами, в то время как для государства-преемника «выражение подтверждения правопреемства в отношении договоров государства-предшественника является необходимым» ${ }^{9}$.

Применительно к договорам, не находившимся в силе в момент правопреемства, и договорам, подписанным под условием ратификации, принятия или утверждения, существует разница между разделением и отделением, хотя прямо это не сказано. При отделении государство-предшественник продолtжает быть связанным договорами, не находившимися в силе в момент правопреемства, на обязательность которых оно уже согласилось (ст. 36), и, пока договор не вступил в силу, оно «обязано воздерживаться от действий, которые лишили бы договор его объекта и цели» (ст. 18 Венской конвенции о праве международных договоров). С другой стороны, государствупреемнику предоставляется право выбора - стать или нет договаривающимся государством или участником договора в случае, если он вступает в силу после момента правопреемства. Исключение из этого правила составляет случай, когда договор принадлежит к категории многосторонних договоров с ограниченным числом участников. В этом случае новые государства нуждаются в согласии всех участников или договаривающихся государств, чтобы установить свой статус в качестве участника или договаривающегося государства этого договора. Второе исключение предусмотрено, когда применение договора в отношении государства-преемника несовместимо с объектом и целями этого договора или коренным образом изменило бы условия его действия (ст. 36).

По статье 37 конвенции за каждым государством, являющимся либо предшественником, либо преемником, сохраняется право ратифицировать, принять или утвердить договор, с той разницей, что в отношении государсгва-преемника существуют два исключения из этого правила, подобные тем, которые существуют в случае договоров, не находившихся в силе в момент правопреемства.

В Венской конвенции о правопреемстве государств в отношении государственной собственности, государственных архивов и государственных долгов регулирование преемства прав и обязанностей находится в прямой зависимости от правосубъектности государства-предшественника. Здесь. по- 
следствия правопреемства государства различаются в зависимости от того, что происходит -- разделение или отделение части его территории.

Относительно государственной собственности продолжение существования государства-предшественника имеет особое значение, когда обсуждается судьба недвижимой государственной собственности государства-предшественника, находящейся за пределами его территории (как, например, его заграничные представительства). При разделении недвижимая собственность переходит к государствам-преемникам в справедливой доле, а при отделении остается у государства-предшественника, и, если государства не условились иначе, вопрос o ее делении не встает (ст. 17-18).

Применительно к государственным архивам продолжение существования государства-предшественника имеет решающее значение в отношении тех архивов, которые не включаются ни в категорию архивов, обеспечивающих нормальное управление территорией государства-преемника, ни в категорию архивов, имеющих непосредственное отношение к территории государства-преемника. Эти архивы в случае разделения переходят к новым государствам «справедливым образом с учетом всех соответствующих обстоятельств»; при отделении, если государства не договорились об ином, продолжают принаддлежать государству-предшшественнику (ст. 30-31). Важно также положение о том, что в отношении государственной собственности и архивов государство-предшественник, если оно есть, является ответственным за их сохранение и невредимость, пока не будет осушествлен переход к государствупреемнику (ст. 13, 26).

Наконец, по Конвенции 1983 года юридическое исчезновение или продолжение существования государства-предшественника не оказывает влияния на судьбу государственных долгов. Они «переходят к государствам-преемникам в справедливой доле с учетом, в частности, имушества, прав и интересов, которые переходят к государству-преемнику в связи с данным государственным долгом» (ст. 40--41), независимо от того, произошло отделение или разделение государства.

\section{Прекращение существования государства}

Как уже отмечалось. чтобы ответить на вопрос о континуитете правосубъектности государства, нужно определить, когда государство прекрашает существовать.

Исчезновение государства, как и его возникновение,--это прежде всего результат исторических и социальных событий. 
Но международное право не относится безразлично к этим событиям; оно определяет, какие именно из этих событий значимы с юридической стороны, и связывает с ними правовые последствия. Это значит, что международное право указывает, какие факты должны иметься в наличии, чтобы вслед за этим появилось или перестало сушествовать государство как субъект международного права, то есть государство, имеющее возможность участвовать в различных правоотношениях. «Тем самым факт существования государства как явления прежде всего общественного преврашается в факт международно-правовой» ${ }^{10}$.

Согласно традиционной доктрине государство считается существуюшим, если налицо три элемента: территория, население (которые являются его материальными основами) и третий, формальный признак - независимая и самостоятельная политическая власть, или «правопорядок государства» ${ }^{11}$.

Прекращение существования государства связано с утратой одного из этих элементов. Вопрос о том, когда это происходит, не всегда находит одинаково бесспорный ответ.

Неясностей не возникает, когда речь идет о полном исчезновении одного из двух материальных элементов, в случае, например, вымирания населения или гибели территории в результате природных катаклизмов, хотя такие рассуждения имеют, скорее всего, только теоретическое значение.

Также общепризнанным является тезис, по которому конкретные изменения в составе населения или в размере государственной территории не оказывают влияния на правосубъектность государства. Таким образом, увеличение или уменьшение числа населения, эмиграция, территориальные изменения не влияют на юридическую личность общества.

Трудности заключаются в определении того, когда именно формальный элемент государства - его правопорядок - перестает сушествовать. В международно-правовой литературе внимание концентрируется на последствиях, которые оказывают на правопорядок конституционные и территориальные изменения внутри страны. Юристы-международники единодушны в том, что конституционные изменения, осуществляемые мирным путем (такие, как смена правительства), не влекут за собой изменения международно-правового характера. Что касается конституционных изменений, происшедших революционным путем, то мнения расходятся. Одни авторы считают, что такие изменения влияния на международную личность государства не оказывают. Они ссылаются на «непрерывность материальной основы государства, то есть на тот факт, что население постоянно пребывает на одной территории» ${ }^{12}$, и на то, что каждый народ «несет ответственность за свое прави- 
тельство». Следовательно, перемена власти не затрагивает наложенных обязательств ${ }^{13}$. Такой подход разделяется и в работах некоторых советских авторов (Е. А. Коровин и Ф. И. Кожевников).

Другие юристы-международники, среди которых Г. Кельзен, Меркль и С. Б. Крылов, стоят на позиции того, что нарушение внутригосударственной правовой непрерывности между старой и новой конституциями подрывает юридическую личность государства. Они указывают на то, что в подобном случае происходит изменение всей системы правоотношений, а не только смена лиц одной и той же социальной группы в правлении государством.

Такого разногласия не встречается, когда речь идет о территориальных изменениях. Считается, что уменьшение или увеличение территории не приводит к подрыву юридической личности государства. Однако, очевидно, существует предел территориальных изменений, переступая который государство перестает быть тем же самым субъектом права. Но международно-правовая практика по этому поводу противоречива. Индия, например, сохранила свою правосубъектность, несмотря на отделение от нее весьма значительной территории, на которой образовалось государство Пакистан. При разделении федерации Мали был выбран другой путь. «Как отделившаяся часть - Сенегал, так и оставшаяся - бывший французский Судан, который стал называться Республикой Мали, должны были снова просить о приеме в ООН, хотя с правовой стороны этот случай принципиально не отличается от случая Индия Пакистан» ${ }^{14}$. В этом случае отделение части территории повлекло за собой юридическое исчезновение государства.

Международное право не содержит ни конвенционных, ни обычных норм, устанавливающих четкие критерии прекращения существования государства. На практике подход выбирается исходя часто из конкретных обстоятельств. Это не позволяет разрешать возникающие вопросы, опираясь только на правовые критерии, а оставляет место для маневрирования по политическим соображениям.

\section{Теория континуитета применительно к государствам - участникам СНГ}

Является ли Россия государством, продолжающим Союз ССР? Вопрос представляется спорным и сложным, особенно потому, что он приобрел интенсивную политическую окраску и в последнее время часто находится в центре 
внимания внешнеполитической деятельности многих стран. Но это виолне естественно, учитывая важность и актуальность этого вопроса после разделения СССР.

Отправным пунктом рассмотрения проблемы должно служить выяснение сути заданного вопроса. Тезис о том, что Россия выступает как «государство, продолжающее Союз ССР в международно-правовом плане», означает, что Россия осуществила континуитет, то есть унаследовала международноправовую личность Союза ССР. Это говорит о том, что международно-правовая личность СССР не прервалась, что СССР как субъект международного права не перестал сушествовать. В случае юридического исчезновения СССР нельзя было бы говорить о продолжении его правосубъектности. СССР в отношении России являлся бы другим государством, а при наличии двух государств в отношении той же территории, одно из которых предшесгвовало другому, встает проблема правопреемства. К тому же если происходит отделение части или частей территории (а не разделение государства) и «личность подвергшегося разделу государства сохраняется, то имеет место только частичное, а не полное правопреемство" " ${ }^{15}$. Россия продолжает осуществлять все права и обязанности СССР, за исключением тех, которые связаны с отделившейся территорией. Таким образом, проблема правопреемства в отношении территории России не встает. В отношении частей территории, которые отделились, Россия выступает как государство-предшественник, которое сохранило свою правосубъектность и продолжает существовать, в то время как остальные новые государства выступают как преемники. Такой подход к проблеме, основанный на континуитете России, ведет к тому, что Россия не является государством-преемником; она не может быть одновременно и государством-предшественником в отношении всей территории Союза ССР и государствомправопреемником в отношении какой-либо территории, так как она не может быть государсгвом-предшественником применительно к одной проблеме и государством-преемником применительно к другой.

Возможен, конечно, и другой подход. Как было написано в Соглашении о создании Содружесгва Независимых Государств, Союз ССР-- государство-предшественник - прекратил существование не только как геополитическая реальность, но и как субъект международного права. Это значит, что при юридическом исчезновении государства-предшественника на территории СССР произошло разделение государства. Так как юридическую личность государства никто не наследовал, то все новые государства выстунают как государствапреемники. 
Сторонники концепции континуитета обращаются не только к правовым нормам, но и к геополитическим и экономическим обстоятельствам, чтобы аргументировать свою позицию. «Правосубъектность Союза перешла к России как к тому государству - участнику СНГ, которое в силу политических, экономических и правовых обстоятельств реально может нести обязательства бывшего Союза» ${ }^{16}$.

Традиционная доктрина рассматривала всегда расчленение государства и появление новых государств как один из случаев прекращения существования государства. Практика, как выше было упомянуто, все-таки не была столь однозначной. «Юридическая техника может пойти по пути признания непрерывности в одних случаях и отрицания в других» ${ }^{17}$. И это часто связано с политическими факторами. Турецкая республика была признана продолжателем Оттоманской империи, но после распада объединенного государства Египта и Сирии в 1961 году никто не наследовал его юридическую Јичность.

Во многих случаях неясность в сушествовании государства как субъекта международного права решается международными соглашениями заинтересованных государств, актами международных организаций или решениями международных судебных органов, хотя часто споры вокруг правосубъектности не успокаиваются и после подобных актов.

Таким образом, судьба международной личности Австрии и Венгрии после распада Австро-Венгерской монархии была решена Сен-Жерменским и Трианонским договорами 1919 года; будущее Индии было рассмотрено ООН; Германо-Югославский смешанный третейский суд по делу создания Югославии в 1918 году постановил, что Королевство сербов, хорватов и словенов не является новым государством.

В случае распада СССР были приняты подобные соглашения-Соглашение о создании СНГ от 8 декабря 1991 г. и Соглашение глав государств в Алма-Ате от 21 декабря 1991 г. Важно подчеркнуть, что в них участвовали все государства, за исключением Грузии, которые в тот момент являлись республиками в составе СССР (статус Прибалтийских государств как государств - преемников СССР был решен раныше, 5 сентября 1991 Г., когда Государственным Советом СССР они были признаны как независимые государства, отделившиеся от СССР). По этим соглашениям международноправовая личность Ссюза ССР не перешла к Содружеству Независимых Государств- она была, признана, как уже говорилось, прекрашенной. Решение о продолжении Россией членства СССР в ООН и в других международных организациях касалось конкретного вопроса, и нам представляется, 
что расширенно толковать его как отправную точку для того, чтобы рассматривать Россию не только как государствопреемника, но и как государство, продолжающее осуществлять права и обязанности СССР, недопустимо.

Кроме того, последующая практика государств пошла по пути отдельного рассмотрения каждого возникающего вопроса. Такой подход был избран и в отношении ядерного оружия, размещенного на территории бывшего СССР. Чтобы предотвратить нарушение соглашения 1968 года о нераспространении ядерного оружия, было достигнуто соглашение о том, что «будет подписан протокол $\mathrm{k}$ договору, по которому Казахстан заявит о готовности уничтожить имеющиеся у него ракеты в течение семи лет» и в котором будет утвержден его статус как неядерного государства. Кроме Казахстана в специальном письме своего президента Украина также обязалась подписать с СШІА подобный протокол ${ }^{18}$. Можно сделать вывод, что заявление России о том, что она «продолжает осуществлять права и обязанности СССР» ( в ноте другим государствам от 13 января 1992 г.), не считалось достаточным для решения Bonpoca.

К тому же одностороннее принятие Россией на себя ответственности за внешние долги бывшего СССР не означает само по себе, что Россия осуществляет континуитет. Так, принятие на себя ФРГ ответственности за внешние довоенные долги Германского государства не влекло за собой признания ФРГ государством, идентичным Германской империи ${ }^{19}$. Тем более упомянутый односторонний акт России не может иметь международно-правовых последствий, когда поступают протесты со стороны других государств СНГ.

Есть еще одна интересная сторона проблемы континуитета. Континуитет представляет собой продолжение осуществления всех прав и обязанностей государства-предшественника. А может ли одно из государств-бывших советских республик нести все эти обязательства? Такой вопрос встает в отношении советско-американского соглашения об уничтожении и запрешении производства химического оружия. «Рассматривая причины неготовности России в выполнении графика уничтожения отравляющих веществ, необходимо прежде всего указать на то, что в момент подписания соглашения существовало единое государство-СССР, которое в то время имело достаточные финансовые и экономические возможнности, необходимые производственные мощности, высокий технический потенциал. Из этого и исходили участники подготовки соглашения при определении сроков уничтожения оружия) ${ }^{20}$. Сегодня, после раздела СССР, только совместными усилиями можно обеспечить выполнение этих и осталь- 
ных договоров, подписанных Союзом ССР, столь важных для всего международного сообщества.

Надо заметить, что вопрос о континуитете возникает не только применительно к СССР и России. Вопрос непрерывности международной правосубъектности должен быть рассмотрен и применительно к РСФСР и Российской Федерации, УССР и Украине, БССР и Республике Беларусь. Была ли, например, БССР субъектом международного права и, в случае положительного ответа, является ли Республика Беларусь тем же самым субъектом международного права, что и БССР,-и тогда не возникает вопроса о правопреемстве в отношении договоров, которые БССР подписала,- или произошел один из случаев фактического правопреемства и вслед за этим ставится вопрос перехода прав и обязанностей, взятых на себя БССР?

Некоторые ученые включают случай изменения международной правосубъектности государства, связанного с изменением международной договорной компетенции, в ситуацию фактического правопреемства. Такое изменение происходит, например, «при образовании федерации, вхождении в нее, при распаде федерации или при выходе из нее--если члены сохранили свою правосубъектность» ${ }^{21}$.

Другие авторы отрицают, что эта ситуация представляет собой фактическое правопреемство ${ }^{22}$. Они считают, что в таком случае государство и после выхода, например, из федерации сохраняет неизменной свою правосубъектность, остается одним и тем же субъектом права.

Думается, что, если положительно отвечать на вопрос о международной правосубъектности бывших советских республик, надо признать и то, что, поскольку материальная основа государств и их правопорядок остались неизменными после распада СССР, государства - преемники СССР продолжают правосубъектность бывших союзных республик, то есть осушествляют континуитет. В этом отношении проблемы правопреемства не встают, потому что сохраняется носитель прав и обязательств.

Как показывает история международных отношений, вопросы правосубъектности остаются на долгое время спорными и нерешенными. Скорее всего, то же самое будет 
и в отношении правосубъектности СССР и его правопреемников. Процесс предстоит длинный и трудный. Тем не менее предпринятые до сегодняшнего дня попытки преодоления возникающих в связи с распадом СССР вопросов показывают, что решение подобных сложных проблем в одностороннем порядке, .руководствуясь не правовыми критериями, а политическими соображениями, чревато опасностью конфликтов и произвола.

Рассмотрение же всех новых государств на территории СССР в качестве его правопреемников, имеющих одинаковый международно-правовой статус и разделяюших в равной мере ответственность за выполнение обязательств СССР, наоборот, подталкивает „к поиску решений согласованными действиями.

Это очень важно не только в интересах государств - преемников СССР, но и для всего международного сообщества. Члены международного сообщества государств заинтересованы в выполнении всех обязательств, которые принял на себя СССР в отношении всей его территории, а не только какой-то части, в целях стабильности международного права, укрепления международного мира и развития международного сотрудничества.

1 Дипломатический вестник.- 1992.- № 1.-С. 3.

2 См. О международно-правовом статусе России и других государств - участников СНГ как государств - правопреемников СССР // Дипломатический вестник.-1992.- № 2-3.-С. $28-29$.

C. $8-9$.

Захарова Н. В. Правопреемство государств.-М., 1973.--

4 Там же.-- C. 11.

5 Предисловие Барсегова Ю. Г. к кн.: О'Конелл. Правопреемство государств.- М., 1957.-С. 9.

6 См. О'Конелл. Указ. соч.-С. 34.

7 Digest of International law / Edited and prepared under the direction M. Whiteman.- Vol. 2.-Wash., 1963.-P. 754.

${ }^{8}$ Колосов Ю. М. Нельзя просто взять и уйти //Советская Россия.- 1991.-- 7 дек.

${ }_{9}$ Клименко Б. М. ПІроблемы правопреемства на территории бывшего Союза ССР// Московский журнал международного права.1992.- № 1.-C. 13.

${ }_{10}$ Фердросс А. Международное право.-- М., 1961.-- С. 224.

C. 177.

11 Анцилотти Д. Курс международного права.-- Т. 1.-- М., 1961.--

${ }_{12}$ Там же.

13 Фердросс А. Указ. соч.-- С. 230. 
14 Аваков М. М. Правопреемство освободившихся государств.M., 1983.-C. 37.

is О'Конелл. Указ. соч.-- С. 36.

16 О международно-правовом статусе Россия и других государств участников СНГ как государств - правопреемников СССР.-С. 29.

17 Броунли Я. Международное право.-Т. 1.-М., 1977.-С. 140.

18 Правда. - 1992.-21 мая.

19 Захарова Н. В. Указ. соч.- C. 31.

20 Известия. - 1992.-27 anp.

21 Захарова Н. В. Указ. соч.-С. 15.

22 Власова Л. В. Правопреемство государств в отношении договоров.- Минск, 1982.--С. 21. 